\title{
JUIZADOS ESPECIAIS CRIMINAIS \\ ANÁLISE SOB A ÓTICA SOCIOLÓGICA DE DURKHEIM E SEU CONCEITO DE SOLIDARIEDADE ORGÂNICA
}

\begin{abstract}
Bianca de Freitas Mazur
Bacharel em Direito pela UFPR, Mestranda em Direito da UFPR, Oficial

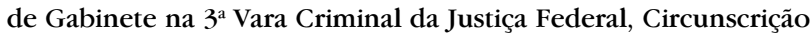
Judiciária de Curitiba.
\end{abstract}

SUMÁRIO: 1 Observações preliminares; 1 .1 Solidariedade mecânica e solidariedade orgânica; 1.2 Direito repressivo e solidariedade orgânica; 1.3 A solidariedade orgânica sob a ótica jurídico-criminal; 2 Juizados especiais criminais; 2.1 Crimes de menor potencial ofensivo; 2.2 A criação dos juizados especiais criminais e seu papel na sociedade; Conclusão; Referências bibliográficas.

\section{OBSERVAÇÕES PRELIMINARES}

Inicialmente, mister se faz que seja apresentada uma justificativa do presente estudo, no qual se busca, a partir da ótica da sociologia, entender as mudanças ocorridas no âmbito do Direito Penal que teriam levado à introdução de novos conceitos e à mudança de tratamento dada pela sociedade e pelos próprios julgadores relativamente a determinados delitos considerados como crimes de menor potencial ofensivo. Verificase, assim, uma relação direta entre as novas tendências do Direito Penal e a Sociologia do Direito, o que se pretenderá demonstrar a partir do conceito de solidariedade orgânica na forma como apresentado por ÉMILE DURKHEIM, cuja concepção incutiu uma nova significação à análise do tipo moderno de sociedade estruturado pluralisticamente, ${ }^{1}$ contribuindo para a "modernização" do Direito Criminal brasileiro, particularmente com a instituição dos chamados Juizados Especiais Criminais.

\subsection{Solidariedade mecânica e solidariedade orgânica}

ÉMILE DURKHEIM, a partir de um estudo sobre a divisão do trabalho social, desenvolveu os conceitos de solidariedade mecânica e solidariedade orgânica. Dividiu seu trabalho em basicamente três partes, determinando primeiramente a função da divisão do trabalho, ou seja, a que necessidade social corresponde; identificando as causas e as condições de que depende; e classificando as formas anormais que a divisão apresenta, uma vez que é a partir da patologia que se vai compreender o fisiológico.

Identificando a função da divisão do trabalho social, que consiste na verificação das necessidades sociais a que se vincula, DURKHEIM vai concluir ser a divisão do

1 PARSONS, Talcott. Durkheim e a teoria da integração dos sistemas sociais. Apud COHN, Gabriel. 
trabalho a principal fonte da solidariedade social, simbolizada externamente pelo direito. A partir dessa constatação, duas hipóteses são formuladas: quanto mais solidários são os membros de uma sociedade, mais relações distintas sustentam entre si ou com outras coletividades; e o número dessas relações é diretamente proporcional às regras jurídicas que as determinam. Ademais, a forma de garantia da solidariedade é a própria coesão social, de forma que devem estar refletidas no direito todas as variantes possíveis da solidariedade social.

Segundo DURKHEIM, existem duas espécies de solidariedade social, a cada qual corresponde uma espécie de sanção, forma segundo a qual classifica as normas jurídicas. Essa relação entre solidariedade-sanção é fundamental à compreensão da teoria de DURKHEIM, uma vez que se é o Direito quem externamente reproduz a solidariedade social, todas as suas normas devem ser capazes de expressar as diferentes variantes da solidariedade e, dessa forma, na medida em que as normas jurídicas são classificadas segundo as diversas sanções, a cada sanção irá necessariamente corresponder uma espécie de solidariedade, sendo imprescindível compreender o conceito de cada uma das espécies de sanção existentes.

As sanções repressivas, aplicadas no direito penal, são aquelas que consistem essencialmente em dor ou ao menos numa perda, numa diminuição imposta ao agente responsável pela prática do delito. Têm por objetivo atingir o agente em sua honra, fortuna, liberdade, vida, enfim, privá-lo de algo que desfruta.

As sanções restitutivas, por sua vez, constituem apenas a exigência da reparação do status quo, ou seja, o restabelecimento das relações perturbadas sob sua forma normal, quer pela recondução à força ao tipo de que desviou, quer por sua anulação (privação de todo e qualquer valor social). Corresponde ao direito restitutivo, que engloba o direito civil, o direito comercial, o direito processual, o direito administrativo e constitucional, sem levar em consideração os comprometimentos de ordem penal que deles decorram.

Às sanções repressivas corresponde a solidariedade mecânica e às restitutivas a solidariedade orgânica.

Segundo DURKHEIM, existe no seio da sociedade uma "consciência coletiva" ou "comum", que consiste no "conjunto de crenças e de sentimentos comuns à média dos membros de uma mesma sociedade, que forma um sistema determinado com vida própria". ${ }^{2}$ Nesse sentido, essa consciência coletiva independe das condições particulares existentes em cada um dos indivíduos, chegando mesmo a formar o "tipo psíquico" da sociedade. Deve-se considerar ainda que cada integrante da sociedade possui uma consciência individual que, não obstante, é solidária àquela consciência coletiva, produzindo o que DURKHEIM vai chamar de solidariedade mecânica. Esta, portanto, liga diretamente o indivíduo à sociedade em que está inserido, de forma que qualquer ato ofensivo à integridade e às regras de conduta estabelecidas para uma vida pacífica 
e possível naquela sociedade, ato este considerado contrário aos valores estabelecidos pela "consciência coletiva" e cuja tutela restou codificada em um estatuto repressivo, implica necessariamente uma resposta repressiva por parte daquela mesma sociedade, resposta esta que é atribuída ao Estado, mediante a aplicação ao suposto autor do delito da pena a ele cominada. A pena, portanto, sob a ótica apresentada por DURKHEIM, consiste numa reação integralmente mecânica à violação por determinado indivíduo das normas estipuladas para a convivência social, mas desempenha um papel fundamental à manutenção da coesão social.

O direito repressivo, dessa forma, é o veículo de expressão daquele tipo de solidariedade social ao qual DURKHEIM vai chamar de solidariedade mecânica e a ruptura de determinado vínculo existente nessa solidariedade é o que constitui o crime. Afinal, o crime consiste justamente na ofensa, num determinado grau de intensidade, aos sentimentos coletivos, capaz de efetivamente comprometer o correto funcionamento da sociedade a qual, como reação, vai exigir do Estado uma resposta concreta àquela violação.

Paralelamente a essa consciência coletiva e à reação mecânica que exsurge na sociedade frente à ruptura de determinado vínculo responsável pela manutenção da solidariedade, consistente na prática de atos criminosos, reconhece DURKHEIM uma solidariedade orgânica, decorrente da divisão social do trabalho e da conseqüente especialização das funções. Aludida solidariedade é expressa pelo direito cooperativo e, contrariamente ao que ocorre no direito repressivo, suas sanções são restitutivas. Nesse sentido, o que a distingue da solidariedade mecânica é o fato de não ser expiatória, reduzindo-se a uma simples restauração.

A explicação dada por DURKHEIM é de que a especialização das funções implica a redução da consciência comum, limitando-se a relação a cada vez mais um menor número de pessoas, razão por que não se justifica possuírem as sanções necessárias o mesmo caráter expiatório que aquelas do direito repressivo. Os bens e objetos tutelados não estão permanentemente na consciência comum, de forma que a violação das regras aqui estabelecidas determina tão-somente uma reação moderada. A partir do grau de desenvolvimento do direito cooperativo existente em cada sociedade, com suas sanções restitutivas, é possível portanto medir o grau de concentração por cada uma alcançado.

Essa solidariedade orgânica, produzida pela divisão do trabalho, supõe necessariamente a diferença entre os indivíduos, de forma que cada um deve ter uma esfera própria de ação e, em conseqüência, uma personalidade. As funções especiais que passam a ser desenvolvidas por cada um se estabelecem nos espaços não ocupados pela consciência coletiva, assegurando sua autonomia e acentuando, quanto mais especializadas forem suas funções, a sua unidade.

Aludida solidariedade, portanto, supõe a diferença entre os indivíduos. Contrariamente à solidariedade mecânica que só é possível na medida em que a personalidade individual seja absorvida pela personalidade coletiva, ela só é possível 
se cada indivíduo tiver uma esfera própria de ação e, conseqüentemente, uma personalidade. $^{3}$

Embora a solidariedade mecânica, representada e expressada pelo direito repressivo, tenha por função manter a coesão social em decorrência das sanções que impõe face à violação das normas criminais, a coesão que resulta da solidariedade orgânica é muito mais forte. Afinal, cada um depende mais estreitamente da sociedade onde o trabalho é mais dividido e a atividade de cada um é tanto mais pessoal quanto mais especializada ela seja. ${ }^{4}$ Quanto mais lugar a individualidade do indivíduo tiver dentro da sociedade, mais torna-se esta capaz de se mover, eis que cada um de seus elementos tem mais movimentos próprios.

\subsection{Direito repressivo e solidariedade orgânica}

A partir dos conceitos acima desenvolvidos, pode-se concluir, numa transposição para o Direito, como DURKHEIM:

“(...) sabemos sob que formas exteriores são simbolizados esses dois tipos de solidariedade, isto é, qual é o corpo de regras jurídicas que corresponde a cada uma delas. Por conseguinte, para conhecer sua importância respectiva num tipo social dado, basta comparar a extensão respectiva dos dois tipos de direito que exprimem, pois o direito sempre varia de acordo com as relações sociais que rege."

Assim sendo, a solidariedade mecânica seria simbolizada pelo direito repressivo e a orgânica pelo direito restitutivo, cada qual com seu corpo de regras jurídicas correspondentes. No entanto, embora o direito varie conforme as relações sociais que rege, essas se modificam com o tempo, ocasionando mudanças tanto na consciência individual de cada membro da sociedade, o que vai interferir na solidariedade orgânica expressada por essa sociedade, como e principalmente na consciência coletiva existente, alterando determinados elementos existentes na solidariedade mecânica.

Afinal, como afirmou ERHLICH, ${ }^{5}$ as prescrições jurídicas não comportam em si mesmas todo o direito, eis que este, em decorrência das mudanças ocorridas na sociedade, também muda, não se limitando aos códigos e às legislações escritas, mas se apresentando também sob uma nova forma de acordo com os ditames e as necessidades da sociedade. Nesse sentido, sendo o direito a forma por excelência de expressão da solidariedade social, esta também se modifica, não guardando a necessária correspondência salientada por DURKHEIM.

A esse direito, ERHLICH vai chamar de "direito vivo", cuja tarefa de reconhecimento vai consistir "na compilação do material a partir das leis e na 
determinação de seu conteúdo através da interpretação própria e na aplicação da interpretação na bibliografia e na administração da justiça". ${ }^{6} \mathrm{O}$ "direito vivo" é aquele que expressa a realidade fática e deve ser observado e apreendido pelos aplicadores da lei, uma vez que o que está prescrito nos códigos guarda pouca ou nenhuma relação com o que efetivamente ocorre no cotidiano. Por essa razão, portanto, a ciência jurídica, para ter certo valor, deve atentar a esse fato.

Considerando-se essas situações é que o Direito Penal, em que pesem as tipificações constantes no respectivo estatuto repressivo e as penas a elas cominadas, atentando às reais situações da sociedade, adotou novas posturas, embasadas em princípios e em algumas legislações ordinárias que procuraram se adequar aos novos fatos. Dentre essas posturas, destacamos a criação das chamadas "penas alternativas" e a instituição dos Juizados Especiais.

Afinal, a dogmática penal vinha e em parte ainda vem se apresentando numa situação de desgaste, decorrente da polêmica travada entre os chamados causalistas e finalistas, que levou muitos a sustentarem sua insuficiência e sua desconexão com a realidade social. A dogmática penal acabou se dedicando tão-somente a elaborações abstratas, abandonando as particularidades do caso concreto e fechando as portas a qualquer consideração da realidade social, ${ }^{7}$ despertando a reação de alguns penalistas.

Nesse sentido, releva observar, com MARCOS JOSEGREI DA SILVA, que a questão hoje "pode ser assim resumida: boa parte dos postulados, alguns princípios e a maioria dos paradigmas utilizados em direito penal não servem para espelhar a reprovabilidade social das condutas incriminadas e a sanção respectiva está em completo desacordo com o pós-modernismo.

Impõe-se, pois, a imediata revisão dos princípios que regem o direito penal e o próprio processo penal, para que, assim, seja viabilizada a sobrevivência destes como ramos da ciência jurídica.

O aprisionamento de qualquer um súdito do Estado deve restringir-se ao mínimo indispensável, circunscrevendo-se àqueles cujo convívio social restar absoluta e completamente inviável. O objetivo da ressocialização intra muros viu, de há muito, demonstrada sua falácia; tampouco justifica o encarceramento, simplesmente, o caráter retributivo da pena, face os efeitos nefastos da prisão. Outro princípio há de presidir o norte do legislador na dicção da norma penal e do operador do direito em sua concretude: a recomposição do dano causado, acrescido de pesados acréscimos, a partir da adoção da doutrina dos punitive damages vigente em direito anglo-saxão.

A restrição do exercício de direitos diversos; a perda da disponibilidade e uso de bens adquiridos, direta ou indiretamente, com o produto do delito, independentemente de quem figure como proprietário; a cobrança de pesadas multas que ultrapassem em

6 EHRLICH, E. Idem, p. 373

7 MAÑAS, Carlos Vico. O princípio da insignificância como excludente da tipicidade no direito penal, p. 19. 
muito o valor do proveito obtido com a prática criminosa e a medida radical do confisco são possibilidades que se sugerem, como meio de superação, para a maioria dos crimes - em especial aqueles que lesam a ordem econômica, fiscal ou o patrimônio, público ou privado - do encarceramento celular. Obviamente, algumas imporiam a alteração de preceitos constitucionais, ou, até, a formulação de uma nova ordem dessa espécie. Não se nega isso. Mas a questão, nesse singelo trabalho, é mesmo de lege ferenda, olhada pela ótica da ciência penal.

Afinal, examinada a matéria pelo ângulo da eficácia social da norma e da prevenção geral e especial, (quase) nenhuma conseqüência há quando se remete à instituição prisional o criminoso de quem se sabe os amigos e familiares gozarão das benesses adquiridas como fruto do delito perpetrado. Tão-somente se lhe retirará a dignidade (o que é lamentável, sob todos os aspectos) e a vítima (em muitos casos, a sociedade) permanecerá esquecida.

Nesse contexto, a privação da liberdade deve-se restringir àqueles que se mostrem criminosos graves e contumazes, cuja convivência social seja de tal maneira prejudicial à coletividade que determine sua segregação, com a adoção de critérios e princípios próprios e objetivos para se aferir essa tal condição. Por outro lado, não se deve, em evidente retrocesso histórico, cassar-lhe o direito à progressão de regime, mediante séria e eficiente supervisão estatal, visando a sua gradual (e inegavelmente difícil) reinserção social. ${ }^{8}$

Nesse sentido, portanto, é que determinados fatos que se apresentavam originariamente como extremamente nocivos à sociedade, não mais afetam hoje a "consciência coletiva" como um todo, o que fez com que determinados tipos penais deixassem de representar efetivamente uma ameaça ao bem jurídico então tutelado e passassem a merecer um novo tratamento por parte dos operadores jurídicos, sem, contudo, implicar a sua descriminalização. Afinal, algumas circunstâncias e conseqüências que se apresentam hoje relativamente à pratica de determinados delitos constituem fatos tão irrelevantes que a conseqüente instauração de um processo criminal não só obstaria o regular desenvolvimento do Poder Judiciário, mas, principalmente, estigmatizaria seu agente, conferindo-lhe o caráter de criminoso pela prática de uma conduta incapaz de efetivamente lesar o bem jurídico que se pretendia com o tipo preservar, e que, de certa forma, passou a ser aceita pela sociedade em geral, que não mais lhe confere o mesmo desvalor que outras condutas igualmente típicas.

Importante, todavia, salientar que esse mesmo corpo social que na atualidade passa a encarar tais condutas com um nível mais elevado de tolerância, por outro lado, não expressa o desejo de pura e simplesmente descriminar o agir contrário à norma penal formalmente prevista, por mais paradoxal que essa postura possa parecer.

Com isso, faz-se necessário lançar um novo olhar sobre o problema jurídicopenal surgido, em vista da novel exigência social, que simplesmente requer uma solução diversa daquelas tradicionalmente adotadas em países de inspiração romano-germânica 
e intensa atividade legiferante que usualmente resolvem impasses desse jaez mediante a aplicação do binômio criminalização/descriminalização da conduta.

Ou seja: há de se efetuar a alteração tendo em conta o novo posicionamento social que, como se disse, por um lado, alarga seu grau de tolerância com condutas de há muito tipificadas criminalmente, mas, por outro, não deseja simplesmente sejam elas retiradas do rol de condutas que merecem tratamento mais gravoso do que aquelas típicas historicamente do direito restitutivo.

A partir dessa constatação, portanto, é que exsurge a discussão acerca da efetiva solidariedade que passa a ser então expressada pelo direito repressivo, especialmente nos casos expostos nos dois parágrafos antecedentes. Afinal, na medida em que constatamos que determinados crimes deixaram de ser considerados pela sociedade tal como eram quando juridicamente instituídos, ou seja, não atingem mais a "consciência coletiva", não podemos afirmar, com segurança, que o direito repressivo, ao menos na parte em que se refere àqueles crimes, esteja expressando uma solidariedade mecânica.

A questão está ligada mesmo ao próprio grau de desenvolvimento da sociedade, uma vez que este é tão maior quanto maior predominância tiver em seu seio a solidariedade orgânica. Essa observação pode ser confirmada empiricamente, uma vez que observamos há bem mais tempo nos países desenvolvidos uma atuação mais precisa e efetiva das novas tendências do direito penal.

O direito repressivo, portanto, atendendo às modificações da sociedade, deixou de ser uma expressão somente da solidariedade mecânica, apresentando, sob determinados aspectos e em determinadas ocasiões, um nível tal de evolução e adequação suficiente para expressar uma solidariedade orgânica, atentando à autonomia e à individualidade de cada membro da sociedade.

Hodiernamente, então, a efetivação da aplicação das normas penais passa por duas idéias fundamentais: não se pode punir um comportamento que a sociedade não considera digno de receber a sanção criminal típica; e o Direito Penal não deve se ocupar de bagatelas. Assim considerando, a moderna dogmática passa então a oferecer técnicas sem que, com seu uso, se abra mão da segurança jurídica que deve ser proporcionada pelo sistema - afinal, aceitar-se o novo posicionamento do corpo da coletividade sem emprestar solução jurídica precisa poderia significar uma convulsão social tal que, à vista da própria ambigüidade do entendimento coletivo, ensejaria a que o direito fosse utilizado cada vez mais para fins espúrios ou, tão grave quanto, para a afirmação do grupo hegemônico dominante em desfavor daqueles que estivessem sob seu jugo, quando e como esse desejasse aplicar a lei penal. Dentre essas técnicas é que se pode citar a definição dos delitos de menor potencial ofensivo e a conseqüente instauração dos Juizados Especiais Criminais com todos seus instrumentos jurídicos e princípios norteadores.

\subsection{A solidariedade orgânica sob a ótica jurídico-criminal}

Cumpre referir, apenas a título de esclarecimento, que em que pesem as constatações acima delineadas, uma concepção jurídico-criminal sobre os Juizados Especiais Criminais não excluiu a expressão da solidariedade mecânica. 
Afinal, se o meio de expressão da solidariedade orgânica é o direito restitutivo, como se pode falar em solidariedade orgânica no Direito Criminal sem the negar o caráter de um direito repressivo?

Sociologicamente, como acima se expôs, a solução é encontrada a partir da introdução no Direito Criminal da solidariedade orgânica, explicada pela própria evolução e desenvolvimento daquele direito e sua adequação à nova realidade social. No entanto, sob o aspecto jurídico-criminal, a questão assume outros contornos.

Os Juizados Especiais Criminais propõem ao suposto autor do crime a transação penal, ou seja, o cumprimento de determinadas condições em troca de ter o agente que responder a uma Ação Penal, podendo, ao final, ser condenado ou não.

Nos países desenvolvidos, a proposta de transação penal consiste, na realidade, na aplicação antecipada da pena, reconhecendo-se antecipadamente a culpa do suposto autor do crime (a chamada plea bargaining). Ainda que não haja um processo ordinário, com a produção de provas e a apresentação de alegações pelas partes, não há afronta ao devido processo legal, eis que, em decorrência do procedimento legalmente instituído, o processo é efetivamente instaurado.

A partir da experiência estrangeira, o Direito Penal brasileiro inseriu, por meio da Lei $n^{\circ}$ 9.099/95, atualmente em parte modificada pela recente Lei $n^{\circ} 10.259 / 01$, semelhante instituto para aqueles crimes cuja pena máxima prevista em legislação não ultrapasse dois anos de reclusão, com a particularidade de que, nesses casos, o suposto autor do fato dito criminoso não se declara ou é considerado culpado. Nesses casos, o acusado simplesmente realiza um acordo com o órgão de acusação e concorda em sofrer algumas restrições em seus direitos - que a lei contraditória e equivocadamente denomina 'aplicação imediata da pena', já que sequer houve condenação ou assunção de culpa pelo acusado! - e, uma vez cumprida a condição (que pode ser a reparação do dano, prestação de serviços ou pagamento de importância em dinheiro para uma finalidade social relevante), livrando-se do estigma de estar respondendo a uma acusação ao término da qual poderia ser ou não condenado, de acordo com os institutos tradicionais do direito criminal.

Tanto na fórmula adotada pelo direito estrangeiro quanto naquela adotada pelo nacional, verifica-se que, ainda que exista um procedimento diferente instituído para os casos em que os delitos não merecem mais a mesma resposta que antigamente era exigida pela sociedade, o direito repressivo não deixa de aplicar a devida sanção (em seu sentido restrito no primeiro caso e genérico no segundo) - são estipuladas condições que devem ser cumpridas pelo réu e essas consistem em institutos semelhantes em tudo à aplicação antecipada da pena - e, dessa forma, continua sendo ele o meio de expressão da solidariedade mecânica.

Assim, não se pode falar, pelo prisma meramente jurídico-criminal, que as novas tendências implantadas pelo Direito Criminal estrangeiro em decorrência da imperiosidade social expressam uma solidariedade orgânica, na medida em que não se é negada, em momento algum, a aplicação da devida sanção repressiva. 
No direito brasileiro, contudo, a questão apresenta-se mais complicada. Como já se referiu brevemente acima, embora a legislação ordinária que regula os Juizados Especiais faça menção em um determinado momento à "pena antecipada", a proposta de transação penal oferecida nos processos em trâmite perante os Juizados não consiste na aplicação antecipada da pena, o que levaria ao entendimento de que se está a emitir um pré-juízo de culpabilidade, condenando-se o réu e este assumindo sua culpa mediante a aceitação das condições propostas, o que não é aceito por nosso ordenamento jurídico. O que se pretende é, ante as características do crime a ele atribuído e a quantidade de pena a ele cominada, possibilitar que seu suposto autor substituta o risco de responder a uma ação penal e, eventualmente, ser ao final condenado, pela certeza de que, cumprindo determinadas condições, não possuirá sequer registro de antecedentes criminais.

Dessa forma, portanto, como concebido na legislação brasileira, por se tratar de uma situação em que, mesmo diante do cometimento de um crime, não se aplica a pena, poderíamos dizer que estamos diante de um direito não-repressivo. Nesse caso, perfeitamente possível o entendimento de que o direito expressado pelos Juizados Especiais consiste na expressão pura e simples de uma solidariedade orgânica. No entanto, a negação da existência de um direito repressivo implica a negação do próprio Direito Criminal, o que tornaria inviável a concepção de determinados institutos, como os Juizados Especiais, dentro do âmbito penal.

A questão pode ser solucionada, contudo, se transferirmos o enfoque do Direito Criminal para a pena. Aquele, obviamente, em momento algum abandonará seu caráter repressivo, continuando a ser a forma de expressão da solidariedade mecânica. No entanto, nada impede que sua sanção, no caso a pena, assuma o condão de expressar a solidariedade orgânica, abandonando sua função meramente repressiva para adquirir um caráter restitutivo.

De qualquer forma, ao menos no direito brasileiro, a questão suscitada deve ser compreendida sob a ótica sociológica, mote do presente estudo, que possibilita encarar a expressão da solidariedade orgânica também por meio do direito repressivo, na forma como exposto no item anterior. No entanto, entendemos importante fosse feito um esclarecimento acerca do tratamento dado ao tema sob a ótica jurídico-criminal, até com o fim de se demonstrar a importância da sociologia e de seu estudo para a compreensão de determinados fenômenos que ocorrem em todos os âmbitos do direito e, nesse caso, particularmente, no direito criminal, já que, por aquele enfoque, a questão apresenta-se, ao menos em princípio, sem resposta.

\section{JUIZADOS ESPECIAIS CRIMINAIS}

\subsection{Crimes de menor potencial ofensivo}

Discute-se a aplicação de uma nova política criminal para os crimes de menor potencial ofensivo, haja vista que, ante a moderna concepção de Direito Penal, é 
inquestionável que os autores de lesões a bens jurídicos só podem ser submetidos à pena quando isto seja absolutamente necessário para a ordenada vida em sociedade. ${ }^{9}$

A incriminação só se justifica quando estiver em jogo um bem ou um valor social importante, não podendo alcançar fatos que se situem exclusivamente na ordem moral, nem situações que, embora ilícitas, não atinjam significativamente a ordem externa. ${ }^{10}$

Essa "nova política criminal" requer o exame rigoroso dos casos em que convém impor pena e dos que convém excluir a sanção penal, suprimindo a infração ou, ainda, modificando ou atenuando a pena existente. Fundamenta-se ela "na racional eleição dos bens jurídicos a serem tutelados, evitando-se uma hipertrofia de tipos penais; na proporcionalidade da pena, que deve ajustar-se às funções retributiva e preventiva da resposta penal; e na dignidade da pessoa humana". ${ }^{11}$

A partir disso, a dogmática penal buscou definir aqueles fatos típicos relativamente aos quais não mais se justificava a aplicação de uma sanção repressiva, bastando, no caso, uma sanção restitutiva, dentro do próprio âmbito do direito repressivo. Aqueles fatos típicos foram então definidos como "infrações de menor potencial ofensivo" e seu conceito vem determinado pelas legislações que instituíram os Juizados Especiais nos âmbitos estadual e federal.

O conceito de delito de menor potencial ofensivo, portanto, vem definido em âmbito estadual no art. 61, da Lei $\mathrm{n}^{\circ} 9.099 / 95$, e em âmbito federal pelo art. $2^{\circ}$, parágrafo único, da Lei ${ }^{\circ} 10.259 / 01$. Aludidas disposições legais seguem abaixo transcritas:

"Art. 61. Consideram-se infrações penais de menor potencial ofensivo, para os efeitos desta Lei, as contravenções penais e os crimes a que a lei comine pena máxima não superior a 1 (um) ano, excetuados os casos em que a lei preveja procedimento especial."

“Art. $2^{\circ}$, parágrafo único. Consideram-se infrações de menor potencial ofensivo, para os efeitos desta Lei, os crimes a que a lei comine pena máxima não superior a 2 (dois) anos, ou multa."

Consoante se pode observar, a Lei dos Juizados Especiais Federais trouxe um novo conceito de delito de menor potencial ofensivo, suscitando discussões na doutrina se esse conceito se estenderia ou não aos juizados estaduais. No entanto, aludida discussão não comporta tratamento mais aprofundado no presente estudo, uma vez que desvirtuaria seu objeto de análise.

Atente-se ainda ao fato de que não se deve confundir o conceito de ilícito de menor potencial ofensivo com o crime de bagatela. Neste, pelo princípio da insignificância, há exclusão da tipicidade, conforme doutrina prevalente, é um "não- 
crime", enquanto naquele o fato é típico, devendo seu autor ser submetido a processo e julgamento se não for possível a conciliação ou a transação. ${ }^{12}$

Ambas as expressões são reflexo da moderna dogmática penal, atribuindo ao direito repressivo o papel de expressão também da solidariedade orgânica existente no bojo da sociedade. No entanto, consoante acima se referiu, o presente estudo, tendo em vista seu próprio caráter, limitar-se-á tão-somente à questão dos Juizados Especiais Criminais.

\subsection{A criação dos juizados especiais criminais e seu papel na sociedade}

O surgimento dos Juizados Especiais Criminais, inicialmente chamados de Juizados de Pequenas Causas, em meados da década de 1980, mais do que decorrente de uma preocupação com a celeridade processual ou o desafogamento de centenas de Varas em que se avolumavam feitos de pouca expressividade no seio social, decorreu do imperativo de sobrevivência do próprio Poder Judiciário frente ao crescente descrédito em que se encontrava, tendo em conta a impressão que causava aos potenciais usuários de seus serviços. ${ }^{13}$

Os Juizados Especiais surgiram como uma resposta de modernização, ultrapassando dogmas até então tidos como quase sagrados, norteando-se pela adoção dos princípios da oralidade, simplicidade, informalidade, economia e celeridade processuais e, mais do que aliviarem a carga de trabalho das Varas e Tribunais já existentes, proporcionaram a mediação estatal de maneira absolutamente conveniente e salutar, em vista dos atrativos que trouxeram à enorme gama de seus potenciais usuários, ajustada, assim, às necessidades sociais e aos conflitos existentes. ${ }^{14}$

Elegendo os casos em que a infração deveria ser suprimida e substituída por um benefício àquele a quem supostamente se atribui a prática de um delito criminal, definindo-se quais os tipos penais que seriam atingidos por essa nova concepção, editaram-se as Leis ${ }^{\circ}{ }^{\circ}$ 9.099/95 e 10.259/01, regulamentando os Juizados Especiais Criminais nos âmbitos estadual e federal, respectivamente.

No plano constitucional, a fonte normativa dos juizados criminais está no art. 98, I e parágrafo único, dispondo que:

“Art. 98. A União, no Distrito Federal e nos Territórios, e os Estados criarão:

I - juizados especiais, providos por juízes togados, ou togados e leigos, competentes para a conciliação, o julgamento e a execução de causas cíveis de

12 MIRABETE, Julio Fabbrini. Juizados especiais criminais: comentários, jurisprudência, legislação, p. 32.

13 SILVA, Marcos Josegrei da. Juizados especiais federais criminais: algumas considerações. In: Juizados especiais federais: primeiras impressões, p. 91-92.

14 SILVA, M. J. Idem, p. 93. 
menor complexidade e infrações penais de menor potencial ofensivo, mediante os procedimentos oral e sumaríssimo, permitidos, nas hipóteses previstas em lei, a transação e o julgamento de recursos por turmas de juízes de primeiro grau;

$$
\mathrm{II}-(\ldots) \text {. }
$$

Parágrafo único. Lei Federal disporá sobre a criação de juizados especiais no âmbito da Justiça Federal."

A criação dos Juizados Especiais contribuiu para a incrementação da consolidação do espaço de consenso no Direito brasileiro, subdividindo o sistema penal brasileiro em: a) subsistema clássico - chamado de espaço de conflito, que alberga as infrações penais de grande potencial ofensivo e centra-se na pena de prisão; e b) subsistema consensual - chamado de espaço de consenso, que cuida das infrações penais de menor ou médio potencial ofensivo e tem como base a não-aplicação de pena de prisão, por conseguinte, segue um "novo" devido processo legal (consensual), previsto na Lei $n^{\circ} 9.099 / 95$, que contempla quatro medidas despenalizadoras: composição civil (art. 74), transação penal (art. 76), representação nas lesões corporais (art. 88) e suspensão condicional do processo (art. 89). ${ }^{15}$

\section{CONCLUSÃO}

O estudo da sociologia é fundamental à compreensão do direito e guarda relação, direta ou indiretamente, com a criação de seus institutos. Os conceitos desenvolvidos no âmbito da sociologia podem e devem ser aplicados ao direito, inclusive com o fim de propiciar a adequação deste à realidade social.

Nesse sentido, o presente trabalho teve por fim demonstrar determinados conceitos da sociologia, no caso, aqueles acerca da solidariedade social introduzidos por ÉMILE DURKHEIM, e relacioná-los diretamente ao Direito Criminal.

A partir de um estudo sobre a divisão social do trabalho e entendendo ser inerente à sociedade a existência de uma solidariedade social, DURKHEIM desenvolveu os conceitos de solidariedade mecânica e solidariedade orgânica. Ambas possuem por fim garantir a coesão social, representando aquela um menor grau de desenvolvimento, na medida em que decorre da existência de uma consciência coletiva, ligada por um vínculo cuja ruptura consiste na prática de crime e que merece da sociedade uma sanção repressiva. Esta, por seu turno, respeita a autonomia e a individualidade de cada ser, expressando um direito meramente restitutivo, cuja sanção tem por fím o restabelecimento das relações perturbadas. Os conceitos desenvolvidos por DURKHEIM, portanto, estão diretamente relacionados ao direito, eis que este é forma de expressão daqueles.

O Direito Criminal, repressivo por excelência, é a forma de expressão da solidariedade mecânica. No entanto, tendo em vista a necessidade, por inúmeros motivos,

15 GOMES, Luiz Flávio. Juizados criminais federais, seus reflexos nos juizados estaduais e outros estudos, p. 17-18. 
de modernização do Direito Criminal, este passou também a expressar, em determinadas circunstâncias e sob condições específicas, a solidariedade orgânica.

Afinal, algumas circunstâncias que se apresentavam relativamente à prática de determinados delitos constituíam fatos tão irrelevantes que lhes dar o mesmo tratamento dado àqueles delitos de maior potencial ofensivo era algo absolutamente inviável. A atuação do direito criminal, nesse sentido, precisava se aproximar da realidade social, adequando-se aos novos ditames da sociedade, buscando pôr um meio termo entre a descriminalização de determinadas condutas e a sanção originariamente estipulada que se mostra incompatível com a resposta jurídica atualmente necessária. Sob esse aspecto é que surgiram determinados institutos, definindo certos delitos como crimes de menor potencial ofensivo, que passaram então a receber um novo tratamento por meio da instituição dos Juizados Especiais Criminais.

A criação dos Juizados, portanto, nada mais é do que um exemplo da própria evolução do direito repressivo (leia-se Direito Criminal) que, ponderando determinadas situações, deixa de aplicar uma sanção repressiva para aplicar uma restitutiva e, dessa forma, constituir-se em forma de expressão da solidariedade orgânica.

Embora sob o aspecto jurídico-criminal a questão assuma outros contornos, sociologicamente é plenamente inteligível, consoante se expôs no presente estudo, possibilitando ao operador do direito a compreensão de determinados fenômenos já ocorridos e a possibilidade de desenvolvimento de novos conceitos, aptos a aproximar cada vez mais o Direito Criminal e, num maior âmbito, o ordenamento jurídico como um todo, da sociedade e da exata realidade na qual ela se encontra inserida.

Não se está querendo com isso descriminalizar determinadas condutas até então consideradas crimes só porque à sociedade não assumem elas a mesma relevância e grau de ofensa ao bem jurídico tutelado que, em tempos anteriores, assumiam. O que se pretende - e essa pretensão encontrou seu meio de atuação na solidariedade orgânica é aplicar àquele que supostamente praticou um "delito de menor potencial ofensivo" uma resposta proporcional à sua conduta e que, no caso, não consiste propriamente em uma sanção repressiva.

A expressão de uma solidariedade orgânica também por meio do direito repressivo, nesse sentido, contribui não só à sua própria evolução, mas permite que este atente de forma mais eficaz e absoluta aos princípios que o regem, como o princípio da intervenção mínima do Direito Penal e o princípio da proporcionalidade e, conseqüentemente, aos direitos constitucionalmente garantidos em nosso ordenamento jurídico.

\section{REFERÊNCIAS BIBLIOGRÁFICAS}

DURKHEIM, Émile. Divisão do trabalho social e direito. In: SOUTO, Cláudio; FALCÃO, Joaquim. Sociologia e direito: leituras básicas de sociologia. São Paulo: Livraria Pioneira, 1980.

O que é fato social? In: As regras do método sociológico. Trad. Maria Isaura Pereira de

Queiroz. 6. ed. São Paulo: Companhia Editora Nacional, 1972. 
EHRLICH, Eugen. Fundamentos da sociologia do direito. Brasília: UnB, 1986, cap. XXI, p. 373-388.

GOMES, Luiz Flávio. Juizados criminais federais, seus reflexos nos juizados estaduais e outros estudos. São Paulo: Revista dos Tribunais, 2002.

MAÑAS, Carlos Vico. O princípio da insignificância como excludente da tipicidade no direito penal. São Paulo: Saraiva, 1994.

MIRABETE, Julio Fabbrini. Juizados especiais criminais: comentários, jurisprudência, legislação. São Paulo: Atlas, 1996.

PARSONS, Talcott. Durkheim e a teoria da integração dos sistemas sociais. Apud COHN, Gabriel. Sociologia para ler os clássicos. Rio de Janeiro: Livros Técnicos e Científicos, 1977. RODRIGUES, José Albertino (org.). Durkheim. Trad. Laura Natal Rodrigues. 6. ed. São Paulo: Ática, 1993.

SILVA, Marcos Josegrei da. Juizados especiais federais criminais: algumas considerações. In: TEIXEIRA, Eduardo Didonet (org.). Juizados especiais federais: primeiras impressões. Curitiba: Gênesis, 2001.

. Por um novo direito penal. Disponível em: www.e-juridico.com.br. 